\title{
A statistical examination of the effects of stratospheric sulfate geoengineering on tropical storm genesis
}

\author{
Qin Wang ${ }^{1}$, John C. Moore ${ }^{1,2,3}$, and Duoying $\mathbf{J i}^{1}$ \\ ${ }^{1}$ College of Global Change and Earth System Science, Beijing Normal University, \\ 19 Xinjiekou Wai St., Beijing, 100875, China \\ ${ }^{2}$ Arctic Centre, University of Lapland, P.O. Box 122, 96101 Rovaniemi, Finland \\ ${ }^{3}$ CAS Center for Excellence in Tibetan Plateau Earth Sciences, Beijing, 100101, China
}

Correspondence: John C. Moore (john.moore.bnu@gmail.com)

Received: 6 February 2018 - Discussion started: 27 March 2018

Revised: 24 May 2018 - Accepted: 19 June 2018 - Published: 2 July 2018

\begin{abstract}
The thermodynamics of the ocean and atmosphere partly determine variability in tropical cyclone (TC) number and intensity and are readily accessible from climate model output, but an accurate description of TC variability requires much higher spatial and temporal resolution than the models used in the GeoMIP (Geoengineering Model Intercomparison Project) experiments provide. The genesis potential index (GPI) and ventilation index (VI) are combinations of dynamic and thermodynamic variables that provide proxies for TC activity under different climate states. Here we use five CMIP5 models that have run the RCP4.5 experiment and the GeoMIP stratospheric aerosol injection (SAI) G4 experiment to calculate the two TC indices over the 2020 to 2069 period across the six ocean basins that generate TCs. GPI is consistently and significantly lower under G4 than RCP4.5 in five out of six ocean basins, but it increases under G4 in the South Pacific. The models project potential intensity and relative humidity to be the dominant variables affecting GPI. Changes in vertical wind shear are significant, but it is correlated with relative humidity, though with different relations across both models and ocean basins. We find that tropopause temperature is not a useful addition to sea surface temperature (SST) in projecting TC genesis, perhaps because the earth system models (ESMs) vary in their simulation of the various upper-tropospheric changes induced by the aerosol injection.
\end{abstract}

\section{Introduction}

Anthropogenic greenhouse gas (GHG) emissions are changing climate (IPCC, 2007). The best solution for limiting climate change is to reverse the growth in net GHG emissions. It is doubtful that reductions in emissions can be done fast enough to limit global mean temperature rises to targets such as the 1.5 or $2^{\circ} \mathrm{C}$ pledged at the Paris climate meeting (Rogelj et al., 2015). Geoengineering is the deliberate and large-scale intervention of Earth's climate system to counteract climate warming (Crutzen, 2006; Wigley, 2006). Geoengineering by stratospheric aerosol injection (SAI) attempts to lessen the incoming sunlight to counteract the effect of global warming. The Geoengineering Model Intercomparison Project (GeoMIP) (Kravitz et al., 2011) is a standardized set of experiments designed to homogenize earth system model (ESM) simulations of geoengineered climates and is supported by 15 model groups globally, with further experiments planned under CMIP6 (Kravitz et al., 2015). Climate system thermodynamics will change under SAI geoengineering because the reduction in shortwave radiation is designed to offset increases in long-wave absorption (Huneeus et al., 2014; Kashimura et al., 2017; Visioni, et al., 2017; Russotto and Ackerman, 2018).

Tropical cyclones (TCs) are one of the most disastrous weather phenomena influencing agriculture, human life, and property (Chan et al., 2005). The large-scale changes in surface temperatures under GHG forcing will impact cyclogenesis changing both the frequency and intensity of TCs (Grinsted et al., 2012, 2013). Hence, how TCs would change in a geoengineered world is of general as well as scientific inter- 
est for its enormous social and economic impact. However, since almost all climate models do not, at present, possess the resolution required to simulate directly the response of TCs to changing patterns of radiative forcing, methods that rely on the statistical links between the thermodynamics of the ocean and atmosphere with cyclone dynamics have predominantly been the topic of studies.

Many methods have been used to study the changes in TCs under climate warming. These can be divided into implicit methods, such as the genesis potential index (GPI) and ventilation index (VI) which we focus on here; semi-explicit, such as downscaling (Emanuel, 2006, 2013); and explicit, such as feature-tracking storm systems (Hodges, 1995; Jones et al., 2017). Implicit methods rely on using historical climate and storm records to quantify relationships between TC and key variables such as local, tropical, and global sea surface temperatures (SSTs), and various teleconnection patterns (Grinsted et al., 2012; Emanuel et al., 2008; Landsea, 2005; Gray, 1979). The potential intensity theory (Bister and Emanuel, 1998; Emanuel and Nolan, 2004) predicts the dependence of TC wind speed on the air-sea thermodynamic imbalance and the temperature of the lower stratosphere. For example, many studies suggest that wind shear has an inhibitory effect on the TC activity (Vecchi and Soden, 2007). Others have also identified changes in the large-scale environmental factors influencing tropical storm activity to assess TC changes in the future (Tippett et al., 2011; Grinsted et al., 2013).

While much is known about which factors influence TC cyclogenesis, a quantitative theory is lacking (Emanuel, 2013), so empirical methods have been used to define the relationship between large-scale environmental factors and tropical cyclogenesis. The GPI uses four environmental variables: potential intensity, low-level absolute vorticity, vertical wind shear, and relative humidity. Potential intensity is the maximum sustainable intensity of TCs based on the thermodynamic state of the atmosphere and sea surface, that is the difference between the saturation enthalpy of the sea surface and the moist static energy of the subcloud layer (Riehl, 1950). Tang and Emanuel (2012) introduced the VI, defined as the flux of low-entropy air into a tropical disturbance or $\mathrm{TC}$, because ventilation disrupts the formation of a deep, moist column that is hypothesized to be necessary for the spin-up of the vortex (Bister and Emanuel, 1997; Nolan, 2007; Rappin et al., 2010). For the Atlantic hurricane region, Tippett et al. (2011) formulated a genesis potential index using the relative sea surface temperature, defined as the tropical Atlantic sea surface temperatures minus the tropical mean sea surface temperatures, and mid-level relative humidity in lieu of the potential intensity and non-dimensional entropy deficit, respectively. Dynamic potential intensity is yet another index designed to describe ocean feedbacks on TCs, because storms bring cold, deeper water to the surface, which reduces the potential intensity (Balaguru et al., 2015). These indices represent the thermodynamic and hence seasonal control of TC genesis and not the dynamic develop- ment of individual storms, which is beyond the abilities of most contemporary climate models, in particular those we use here. The relative contribution of the individual largescale environmental factors to TC genesis may be different in different ocean basins (Emanuel, 2010; Wing et al., 2015).

An increase in future global TC frequency has been projected based on dynamical downscaling CMIP5 models (Emanuel, 2013). However, the same downscaling applied to the CMIP3 models projected a decrease in global TC frequency (Tory et al., 2013; Emanuel, 2006). Some models show that, although Atlantic TC frequency will decrease, the frequency of intense TC (those having wind speeds larger than $55 \mathrm{~ms}^{-1}$ ) will increase, and different TC basins are predicted to behave differently (Emanuel et al., 2008; Knutson et al., 2015).

There has been little research about TC changes under SAI. Moore et al. (2015) used the statistical relation between Atlantic tropical storm surges and spatial patterns of global surface temperature to deduce that moderate amounts of SAI could reduce the frequency of the most intense TC relative to GHG-only climates. Jones et al. (2017) showed SAI in the Northern Hemisphere reduced the numbers of TC in the North Atlantic while SAI in the Southern Hemisphere increased numbers in the basin.

In contrast with earlier work that has focused only on the impacts of SAI on North Atlantic hurricanes (Moore et al., 2015; Jones et al., 2017), we examine ESM simulations of the global TC evolution in six ocean basins using the GPI and VI indices. We then evaluate how far TC changes under SAI and GHG forcing can be attributed to thermodynamic changes and hence be forecast in statistical terms.

Section 2 introduces the methods and data used in this study. Section 3 describes the temporal and spatial variations of the GPI and ventilation index in five models, in GHG and SAI simulations. We quantify the contribution of SST, relative humidity, and wind shear to TC genesis based on attribution of monthly variance in GPI and VI in each basin's time series using multiple linear regression methods. Finally, a discussion and conclusions are provided in Sect. 4.

\section{Methods and data}

\subsection{Methods}

We use climate model output from the GeoMIP G4 experiment (Kravitz et al., 2011) and the control simulation, RCP4.5 experiment of CMIP5 (Taylor et al., 2012), to analysis the characteristic of TC changes in the future in different models. The G4 experiment is based on the GHG emissions from the RCP4.5 scenario but shortwave radiative forcing is reduced by injection of $\mathrm{SO}_{2}$ into the equatorial lower stratosphere at altitudes of $16-25 \mathrm{~km}$, at a rate of $5 \mathrm{Tg} \mathrm{yr}^{-1}$ from the year 2020 to 2069 . The experiment continues for a fur- 
Table 1. Climate models used in this study.

\begin{tabular}{llrr}
\hline Model & Reference & $\begin{array}{r}\text { Resolution } \\
(\text { long } \times \text { lat })\end{array}$ & $\begin{array}{r}\text { Ensemble } \\
\text { members }\end{array}$ \\
\hline BNU-ESM & Ji et al. (2014) & $128 \times 64$ & 1 \\
HadGEM2-ES & Collins et al.(2011) & $192 \times 144$ & 3 \\
MIROC-ESM & Watanabe et al. (2011) & $128 \times 64$ & 1 \\
MIROC-ESM-CHEM & Watanabe et al. (2011) & $128 \times 64$ & 9 \\
NorESM1-M & Bentsen et al. (2013) & $144 \times 96$ & 1 \\
\hline
\end{tabular}

Table 2. Definitions of regions and numbers of observed TC.

\begin{tabular}{lrrr}
\hline Region & Latitudes & Longitudes & $\begin{array}{r}\text { Annual mean numbers and } \\
\text { percentages }\end{array}$ \\
& & & $1980-2008)$ \\
\hline North Atlantic (NA) & $6-18^{\circ} \mathrm{N}$ & $20-60^{\circ} \mathrm{W}$ & $12(15 \%)$ \\
Eastern North Pacific (ENP) & $5-16^{\circ} \mathrm{N}$ & $90-170^{\circ} \mathrm{W}$ & $15(19 \%)$ \\
Western North Pacific (WNP) & $5-20^{\circ} \mathrm{N}$ & $110-150^{\circ} \mathrm{E}$ & $25(32 \%)$ \\
North Indian (NI) & $5-20^{\circ} \mathrm{N}$ & $50-110^{\circ} \mathrm{E}$ & $4(5 \%)$ \\
South Indian (SI) & $5-20^{\circ} \mathrm{S}$ & $50-100^{\circ} \mathrm{E}$ & $23(29 \%)$ \\
South Pacific (SP) & $5-20^{\circ} \mathrm{S}$ & $160^{\circ} \mathrm{E}-130^{\circ} \mathrm{W}$ & \\
\hline
\end{tabular}

ther 20 years to 2089 with only GHG forcing as specified by RCP4.5.

We assess the large-scale environmental conditions for TC generation primarily in reference to the widely used genesis potential and ventilation index, and we use the results for the VI for comparison. While other indices also exist as mentioned above, the data fields required to calculate them are presently not all available. The signal-to-noise ratio of the G4 experiment is not as large as that of G1 (Yu et al., 2015) where solar dimming offsets quadrupled $\mathrm{CO}_{2}$ concentrations. It is, however, more interesting for TC studies because the sulfate aerosol injected into the stratosphere causes radiative heating (Pitari et al., 2014) and other indirect effects on the upper troposphere (Visioni et al., 2018) that will potentially affect the deep tropospheric convention systems that characterize intense tropical storms.

The GPI has been widely employed to represent TC activity (e.g., Song et al., 2015), and several different formulations have been described (e.g., Emanuel, 2004, 2010). Here, we chose to use perhaps the most commonly used method (Emanuel, 2004) to calculate the GPI as follows:

$\mathrm{GPI}=\left|10^{5} \eta\right|^{3 / 2}\left(\frac{H}{50}\right)^{3}\left(\frac{V_{\text {pot }}}{70}\right)^{3}\left(1+0.1 V_{\text {shear }}\right)^{-2}$,

where $\eta$ is the absolute vorticity in $\mathrm{s}^{-1}, H$ is the relative humidity at $700 \mathrm{hPa}$ in percent, $V_{\text {pot }}$ is the potential intensity in $\mathrm{ms}^{-1}$, and $V_{\text {shear }}$ is the magnitude of the wind shear from 850 to $200 \mathrm{hPa}$ in $\mathrm{ms}^{-1}$. Potential intensity (Emanuel, 2000) is defined as

$V_{\mathrm{pot}}^{2}=C_{\mathrm{p}}\left(T_{\mathrm{S}}-T_{\mathrm{O}}\right) \frac{T_{\mathrm{S}}}{T_{\mathrm{O}}} \frac{C_{K}}{C_{\mathrm{D}}}\left(\ln \theta_{\mathrm{e}}^{*}-\ln \theta_{\mathrm{e}}\right)$, where $T_{\mathrm{S}}$ is the ocean surface temperature; $T_{\mathrm{O}}$ is the mean outflow temperature, which is taken near the tropopause at the $100 \mathrm{hPa}$ level and spatially averaged (Wing et al., 2015); $C_{\mathrm{p}}$ is the heat capacity of dry air at constant pressure; $C_{K}$ is the exchange coefficient for enthalpy; and $C_{\mathrm{D}}$ is the drag coefficient. $\theta_{\mathrm{e}}^{*}$ is the saturation equivalent potential temperature at the ocean surface and $\theta_{\mathrm{e}}$ is the boundary layer equivalent potential temperature.

We assess the large-scale environmental conditions for TC generation primarily using the GPI but make use of the VI for comparison purposes (Tang and Camargo, 2014), defined as

$\mathrm{VI}=\frac{\chi_{m} V_{\text {shear }}}{V_{\text {pot }}}$,

where $\chi_{m}$ is the (nondimensional) entropy deficit, defined as

$\chi_{m}=\frac{s_{m}^{*}-s_{m}}{s_{\mathrm{SST}}^{*}-s_{\mathrm{b}}}$,

where $s_{m}^{*}$ is the saturation entropy at $600 \mathrm{hPa}$ in the inner core of the TC; $s_{m}$ is the environmental entropy at $600 \mathrm{hPa} ; s_{\mathrm{SST}}^{*}$ is the saturation entropy at the sea surface temperature; and $s_{\mathrm{b}}$ is the entropy of the boundary layer, which we chose as the $925 \mathrm{hPa}$ layer. The numerator of Eq. (4) is the difference in entropy between the TC and the environment at mid-levels, while the denominator is the air-sea disequilibrium; both are calculated following Emanuel (1994). In contrast with GPI where increases correspond to heightened TCs, increases in VI mean fewer TCs are likely. 
Table 3. Differences (G4 - RCP4.5) in TC basins and season during 2020-2069 year calculated point by point. Northern Hemisphere numbers are above and Southern Hemisphere below. GPI and VI are expressed as percentages ((G4 - RCP4.5) / RCP4.5). Bold fonts are significant at $95 \%$ level according to the Wilcoxon signed-rank test.

\begin{tabular}{|c|c|c|c|c|c|c|c|c|c|c|}
\hline Models & $\begin{array}{r}T_{\mathrm{S}} \\
\left({ }^{\circ} \mathrm{C}\right)\end{array}$ & $\begin{array}{r}T_{\mathrm{O}} \\
\left({ }^{\circ} \mathrm{C}\right)\end{array}$ & $\begin{array}{r}T_{\mathrm{S}}-T_{\mathrm{O}} \\
\left({ }^{\circ} \mathrm{C}\right)\end{array}$ & $\begin{array}{l}\text { GPI } \\
(\%)\end{array}$ & $\begin{array}{r}V_{\text {pot }} \\
\left(\mathrm{ms}^{-1}\right)\end{array}$ & $\begin{array}{r}H \\
(\%)\end{array}$ & $\begin{array}{r}V_{\text {shear }} \\
\left(\mathrm{ms}^{-1}\right)\end{array}$ & $\left(\times 10^{-8} \mathrm{~s}^{-1}\right)$ & $\begin{array}{l}\text { VI } \\
(\%)\end{array}$ & $\begin{array}{r}\chi_{m} \\
\left(\times 10^{-3}\right)\end{array}$ \\
\hline \multirow[t]{2}{*}{ BNU-ESM } & $-\mathbf{0 . 5 0}$ & 0.12 & -0.62 & -3.8 & -0.45 & -0.071 & 0.014 & -0.63 & 2.2 & 16 \\
\hline & -0.42 & 0.11 & $-\mathbf{0 . 5 3}$ & 0.37 & 0.070 & 0.20 & -0.27 & -1.0 & -1.5 & 15 \\
\hline \multirow[t]{2}{*}{ MIROC-ESM } & -0.34 & -0.58 & 0.24 & -6.7 & -0.94 & -0.36 & 0.13 & 1.3 & 2.5 & -3.7 \\
\hline & -0.30 & -0.56 & 0.26 & -0.86 & $-\mathbf{0 . 5 0}$ & -0.19 & 0.13 & -2.3 & 2.3 & 6.8 \\
\hline \multirow[t]{2}{*}{ MIROC-ESM-CHEM } & -0.25 & -0.45 & 0.21 & -4.8 & 6.9 & 4.8 & 1.8 & -0.054 & 1.9 & -7.9 \\
\hline & -0.21 & -0.43 & 0.22 & -11 & 6.5 & 3.6 & 2.2 & -0.027 & 1.3 & 3.6 \\
\hline \multirow[t]{2}{*}{ NorESM1-M } & -0.23 & -0.087 & -0.15 & 4.8 & -0.52 & -0.51 & 0.029 & -3.4 & -2.0 & -4.8 \\
\hline & -0.21 & -0.071 & -0.14 & -0.73 & -0.62 & -0.10 & -0.12 & -0.83 & 2.5 & 3.3 \\
\hline \multirow[t]{2}{*}{ HadGEM2-ES } & -0.65 & 0.16 & -0.80 & -3.1 & -1.0 & 0.17 & 0.041 & 1.9 & 3.8 & 35 \\
\hline & -0.61 & 0.15 & -0.76 & 0.39 & -0.71 & -0.088 & -0.079 & 1.0 & 1.1 & 30 \\
\hline \multirow[t]{2}{*}{ Ensemble } & -0.40 & -0.14 & -0.26 & -2.7 & 0.80 & 0.80 & 0.40 & -0.2 & 1.9 & 7.0 \\
\hline & -0.35 & -0.13 & -0.23 & -2.5 & 0.95 & 0.68 & 0.37 & -0.7 & 1.0 & 11.8 \\
\hline
\end{tabular}

Table 4. Difference percentage in GPI and VI calculated as (G4 - RCP4.5) / RCP4.5 over the period 2020-2069 during TC season and basins. GPI are written above VI in each cell. Bold means the difference is significant at the $5 \%$ level according to the Wilcoxon signed-rank test.

\begin{tabular}{|c|c|c|c|c|c|c|c|}
\hline Models & WNP & ENP & NA & NI & SI & SP & All \\
\hline \multirow[t]{2}{*}{ BNU-ESM } & 2.8 & -4.0 & -3.7 & -8.7 & 0.9 & 2.1 & -3.3 \\
\hline & 3.0 & 5.6 & 3.0 & 1.9 & -0.7 & -1.7 & 0.7 \\
\hline \multirow[t]{2}{*}{ MIROC-ESM } & -4.2 & -5.6 & -8.4 & -4.6 & 2.2 & 8.5 & -6.1 \\
\hline & 8.1 & 2.4 & 1.9 & 1.9 & 2.2 & 0.1 & 2.3 \\
\hline \multirow[t]{2}{*}{ MIROC-ESM-CHEM } & -4.1 & -7.7 & -10.2 & -12.2 & -14.0 & -3.0 & -8.6 \\
\hline & -1.7 & -0.9 & 3.9 & 8.0 & 1.2 & 0.3 & 2.0 \\
\hline \multirow[t]{2}{*}{ NorESM1-M } & 0.4 & 37.0 & 9.1 & 11.2 & -0.3 & 3.1 & 0.9 \\
\hline & -1.7 & -8.1 & -1.3 & 6.0 & 4.7 & 1.3 & -0.8 \\
\hline \multirow[t]{2}{*}{ HadGEM2-ES } & 3.2 & -6.8 & -5.2 & -4.2 & -0.7 & 2.1 & -2.3 \\
\hline & 4.0 & 6.0 & 0.9 & 7.1 & 2.5 & 0.1 & 3.0 \\
\hline \multirow[t]{2}{*}{ Ensemble } & -0.4 & 3.3 & -3.7 & -3.7 & -2.4 & 2.6 & -3.9 \\
\hline & 2.3 & 1.0 & 1.7 & 5.0 & 2.0 & 0.5 & 1.5 \\
\hline
\end{tabular}

\subsection{Data}

Although to date eight ESMs have performed the RCP4.5 and G4 simulations, a subset of six models have access to all required model data fields, but one of those, CanESM2, was not used because all three of the realizations of the model failed to pass statistical tests, leaving five models in this study (Table 1). The particular tests we performed to exclude some data and models from the analysis are discussed in detail in Sect. 3.2. The rejected simulations all produced statistically weak and insignificant regression fits to linearized forms of GPI and VI with all combinations of the thermodynamic and dynamic terms used to compute them. Hence, it is unlikely that VI or GPI can meaningfully represent TC activity in these cases. In comparison, the ESM simulations we do use have regression models that are significant at least at the $99.9 \%$ level and, in many cases, achieve far higher significance.

We use monthly sea surface temperature (SST), relative humidity, vertical wind shear, sea level pressure, specific humidity, and air temperature on different vertical levels. All the model outputs at different spatial resolutions were interpolated to a common grid $(128 \times 64)$ using the bilinear interpolation method. All the models were weighted equally in the ensemble mean, so the models with more than a single ensemble member were first averaged before taking the overall model ensemble mean.

\subsection{TC basins}

Factors influencing TC change are diverse across different ocean basins. Some studies (Emanuel, 2010; Knutson et al., 2010) find robust or significant declines in the frequency of events in the Southern Hemisphere, while the Northern 
Hemisphere is relatively constant in the observational record. We therefore examine relationships across all the six TC basins listed in Table 2. The observed TC annual mean numbers for the period 1980-2008 for each basin (Emanuel, 2010) are also listed in Table 2. The North Atlantic makes up a relatively small fraction of the total, with the Pacific dominant in the global locations of TCs.

\section{Results}

The climate response to $\mathrm{G} 4$ forcing has been discussed by $\mathrm{Yu}$ et al. (2015). The general pattern of temperature change under GHG forcing includes accentuated Arctic warming and least warming in the tropics. The G4 experiment largely reverses these changes, but leaves some residual warming in the polar regions and under-cools the tropics. SAI also reduces temperatures over land more than over oceans relative to $\mathrm{GHG}$ and hence reduces the temperature difference between land and oceans. Between 2020 and 2069, SSTs in the six basins during their TC seasons are $0.4{ }^{\circ} \mathrm{C}$ (with a model range of $0.2-0.6^{\circ} \mathrm{C}$ ) warmer in $\mathrm{RCP} 4.5$ than under $\mathrm{G} 4$.

\subsection{The temporal and spatial distribution of GPI and VI}

We list the basin GPI and VI by model and month in Table S1 in the Supplement. The individual monthly GPI values as a fraction of the annual totals are shown in Table S2 in the Supplement. We select the northern and southern TC season on the basis of the each model's monthly fractions of GPI. We use a threshold of $10 \%$ for above uniformly distributed GPI for RCP4.5- and G4-averaged GPI and find that for the northern basins June through November are above the threshold, while for the southern basins it is January through June. Thus, there are 6 months in each hemisphere and they account for $68 \%$ under both RCP4.5 and G4 of the yearly total GPI (Table S3 in the Supplement). We also notice from Table S2 in the Supplement that under G4 the TC season occurs about 1 month earlier than under RCP4.5 in both hemispheres, although our choice of threshold for the TC season means that we can use the same 6 months for each experiment. The same analysis for VI shows similar results, although the season is less well defined than for GPI; for instance, VI in August is higher than December in the northern basins as is January in the southern ones, but the general results do not require separate definitions of season from those for GPI. The Northern Hemisphere peak TC season is June through November and January through June in the Southern Hemisphere; various authors have used longer periods in analyzing model data - e.g., Emanuel (2013) used all 12 months, while Jones et al., (2017) used June-November for the North Atlantic hurricane season. Li et al. (2013) note that the northern Indian TC basin has a secondary peak in TC around May. This peak is reproduced by the BNU-ESM, HadGEM2-ES,
MIROC-ESM, and NorESM1-M models, where it is about half the size of the peak months later in the year (Table S1 in the Supplement). This does not affect the statistical choice of TC months (Table S2 in the Supplement), although it causes the fraction of GPI accounted for in our TC season to be the lowest for the northern Indian basin (Table S3 in the Supplement).

The models we use have considerable range in their absolute values of GPI, which is also a generally observed feature of climate models (Emanuel, 2013). The GPI has a rising trend under RCP4.5 and G4 (Fig. 1). Table 3 shows that there are significantly $(p<0.05$ when tested using the Wilcoxon signed-rank test) lower values of GPI under G4 than RCP4.5 for Northern Hemisphere basins in all models except for NorESM1-M, but only MIROC-ESM-CHEM has significantly lower GPI for the Southern Hemisphere basins. The time series indicate that tropical storms will become more frequent with time and that G4 significantly reduces the numbers.

Figure 1 also shows the evolution of VI in the TC seasons during 2020 to 2069 among the five models. Note that following the definition of VI in Tang and Camargo (2014) we use the median value, not its mean. The model ensemble shows decreasing trends over time, indicating a tendency for more TCs, which is consistent with trends in GPI. Table 3 shows that the G4-RCP4.5 differences in Northern Hemisphere basins are significantly positive except for NorESM1M; Southern Hemisphere basins show less consistent results, which is also consistent with GPI, which indicates that G4 reduces TC occurrence, and is more effective in the Northern Hemisphere.

Figure 2 shows the correlations between the G4-RCP4.5 model differences for annual mean GPI and VI. Most models, and the ensemble, show significant anti-correlation across all TC basins, except the South Pacific where more than half the models have significant correlation. The ensemble mean correlation is only around -0.3 , indicating that GPI and VI are addressing sufficiently different aspects of TC to warrant independent analysis. We next examine the spatial pattern of GPI and VI calculated over the 50-year period: 20202069 in the G4 and RCP4.5 experiments. The relative differences as percentages $\left(\left(\mathrm{GPI}_{G 4}-\mathrm{GPI}_{\mathrm{RCP} 4.5}\right) / \mathrm{GPI}_{\mathrm{RCP} 4.5}\right)$ during the 6 months of each hemisphere's TC season are shown in Fig. 3. These geographic patterns can be compared with the values in Tables 3 and 4.

Figure $3 \mathrm{a}$ shows that the GPI anomaly varies by region and by model. For instance, all models except NorESM1$M$ show negative differences in the North Indian basin. All models except MIROC-ESM-CHEM show the South Pacific to be reddish in color, indicating increased GPI under G4 compared with RCP4.5, which is consistent with Table S1 in the Supplement. Similarly, the northeast Pacific basin has positive differences in MIROC-ESM-CHEM and NorESM1M. Negative differences indicate fewer tropical storms with SAI than under GHG forcing alone. Despite model differ- 

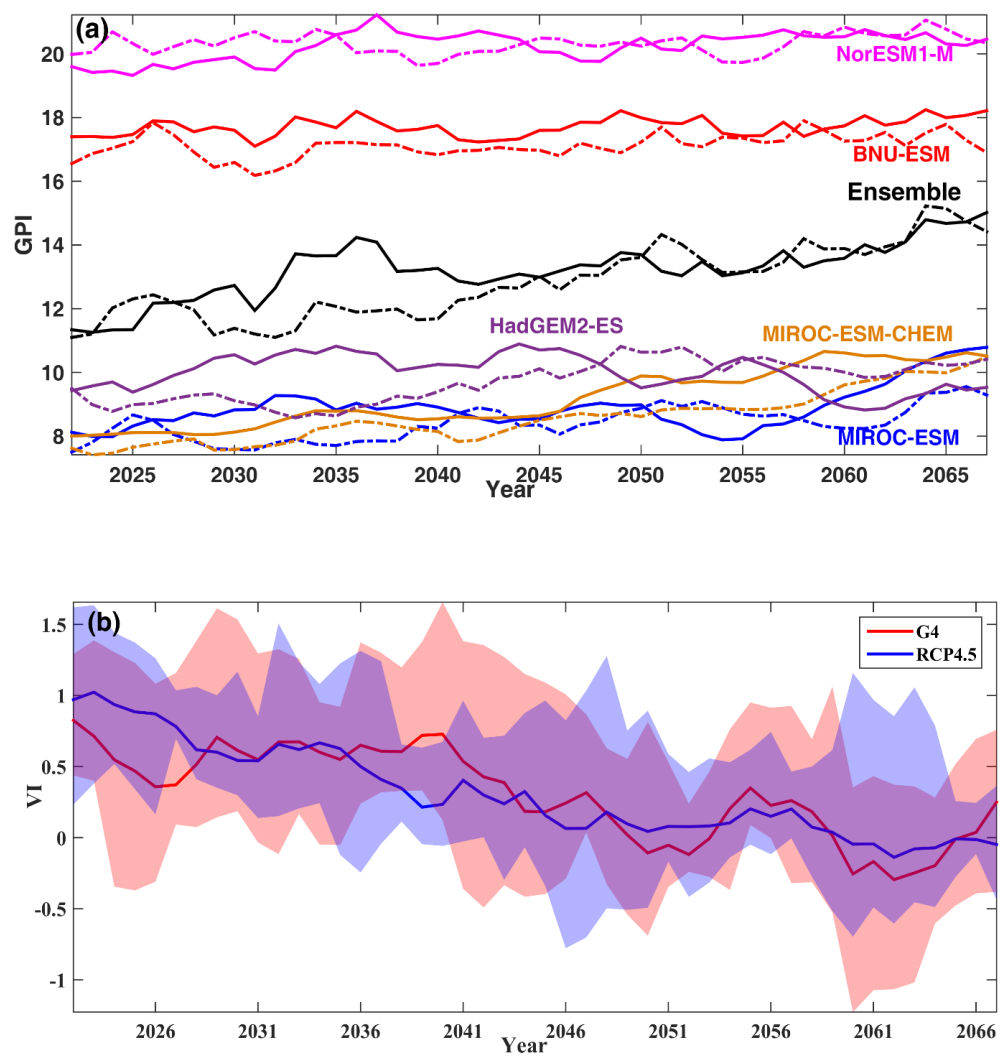

Figure 1. Five yearly moving annual averages across the six TC basins and TC season of (a) normalized GPI shifted by the each model's mean over 2020-2069; solid lines denote forcing under RCP4.5 and dotted lines values under G4. The ensemble was calculated as the mean of normalized models then offset by the mean across-model GPI. (b) VI with solid lines denoting model ensemble means and shading indicating the range across the five models.

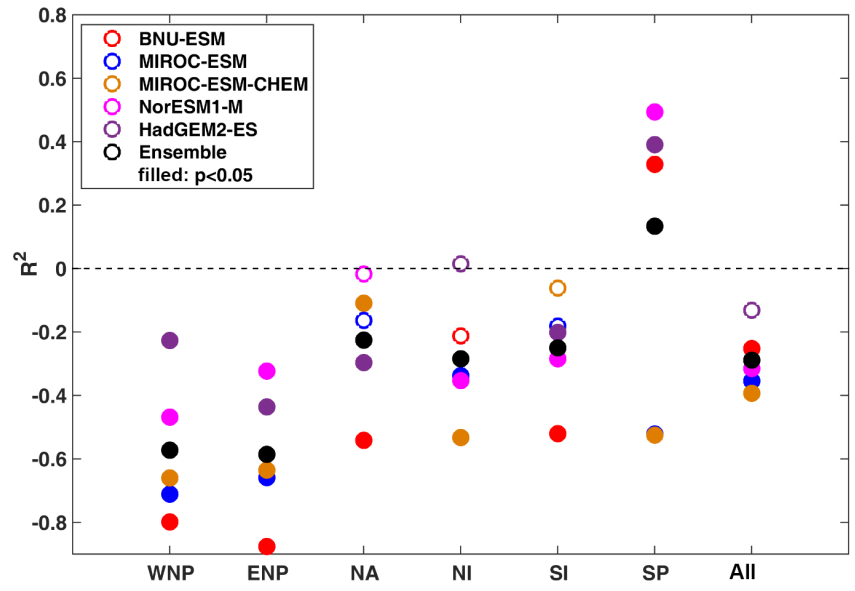

Figure 2. The correlation coefficients $\left(R^{2}\right)$ between annual GPI and VI anomalies (G4 - RCP4.5) during TC season and six ocean TC basins. The MIROC-ESM-CHEM model has four ensemble members, the HadGEM2-ES model has three ensemble members, and other models have one member. Each model is weighted equally and normalized for the ensemble regardless of the number of separate realizations. The dashed line represents $R^{2}=0$. ences, the ensemble result shows robustly that the GPI difference is generally negative in the Northern Hemisphere but insignificantly positive in the South Pacific and northeastern Pacific basins (Table 4). At present the vast majority of tropical storms occur in the Northern Hemisphere (Table 2), so the overall global numbers would likely decrease.

The spatial distribution of VI also has large variation (Fig. 3b). All models except NorESM1-M have increases in the North Atlantic. In the northeast Pacific, all models except MIROC-ESM-CHEM and NorESM1-M have increases. Increased VI differences (G4 - RCP4.5) suggests fewer cyclones in agreement with the results of GPI. In the North Indian Ocean, all models show increased VI difference in the Arabian Sea and all except BNU-ESM and MIROCESM show increased VI difference in the Bay of Bengal. Only MIROC-ESM shows an increase in the South Pacific. The ensemble results are thus largely simply opposite in sign to GPI.

\subsection{Accounting for changes in GPI and VI}

We use two different methods to examine how the contributing climate variables to GPI and VI account for differences 

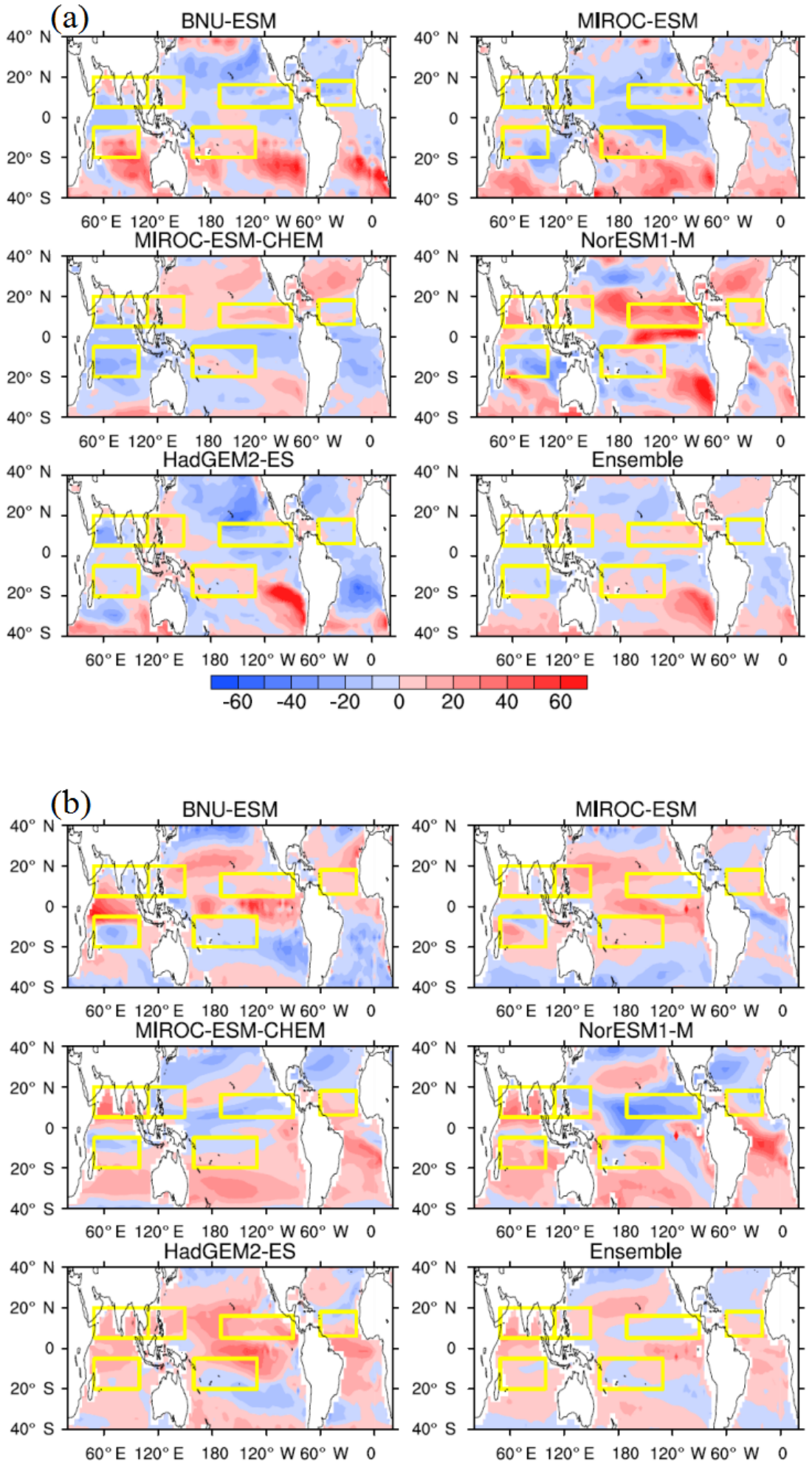

$\begin{array}{lllllll}-24 & -16 & -8 & 0 & 8 & 16 & 24\end{array}$

Figure 3. Spatial distribution at each grid point during the appropriate TC season between 2020 and 2069 of the anomaly as a percentage $\left(\left(\mathrm{GPI}_{\mathrm{G} 4}-\mathrm{GPI}_{\mathrm{RCP} 4.5}\right) / \mathrm{GPI}_{\mathrm{RCP} 4.5}\right)$ for (a) GPI and (b) VI. Yellow rectangles delimit the six TC ocean basins. The Northern Hemisphere TC season is defined as June through November, and the Southern Hemisphere season is defined to be January through June. 

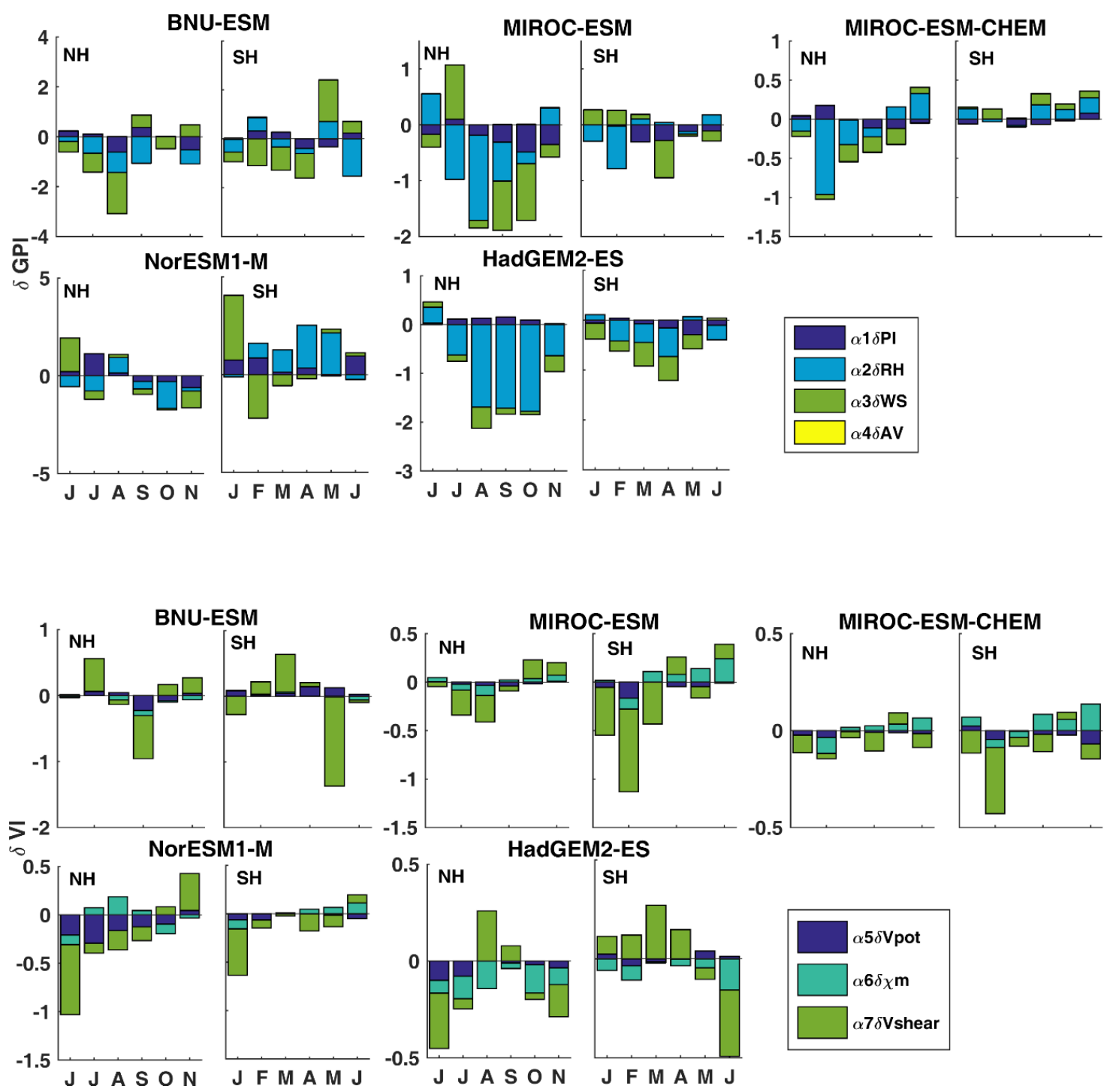

Figure 4. The mean month contribution of each variable to the difference (G4 - RCP4.5) for the years 2020-2069 in TC basins and TC season in GPI and VI.

between models and across the TC basins. The objectives are to (1) learn which are the key variables in the model simulations of cyclones, (2) find a subset that can be tested against the understanding of how SAI affects the atmosphere heat and water balance, and (3) examine if variations in TC basin extent or cyclone seasons may be expected under SAI.

\subsubsection{Monthly differences in GPI and VI components between G4 and RCP4.5}

To examine the effects of SAI on cyclone seasonality, we look at the monthly contributions of the factors that make up GPI and VI. Li et al. (2013) expressed Eq. (1) for GPI as the product of four terms, respectively, representing an atmospheric absolute vorticity term (AV), a vertical wind shear term (WS), a relative humidity term $(\mathrm{RH})$, and an at- mospheric potential intensity term (PI).

$\mathrm{GPI}=\frac{\mathrm{PI} \times \mathrm{RH} \times \mathrm{AV}}{\mathrm{WS}}$,

where $\mathrm{PI}=\left(\frac{\mathrm{Vpot}}{70}\right)^{3}, \mathrm{RH}=\left(\frac{H}{50}\right)^{3}, \mathrm{WS}=\left(1+0.1 V_{\text {shear }}\right)^{2}$, $\mathrm{AV}=\left|10^{5} \eta\right|^{\frac{3}{2}}$.

The AV and WS are considered dynamic components, while the RH and PI are thermodynamic ones. We follow Li et.al. (2013) in identifying the individual monthly contributions from the four large-scale environmental processes. Taking the natural logarithm of both sides of Eq. (5), differentiating, and substituting back into Eq. (5) allows GPI to be expressed as annual means and monthly anomalies:

$\delta \mathrm{GPI}=\alpha_{1} \times \delta \mathrm{PI}+\alpha_{2} \times \delta \mathrm{RH}+\alpha_{3} \times \delta \mathrm{WS}+\alpha_{4} \times \delta \mathrm{AV}$, 


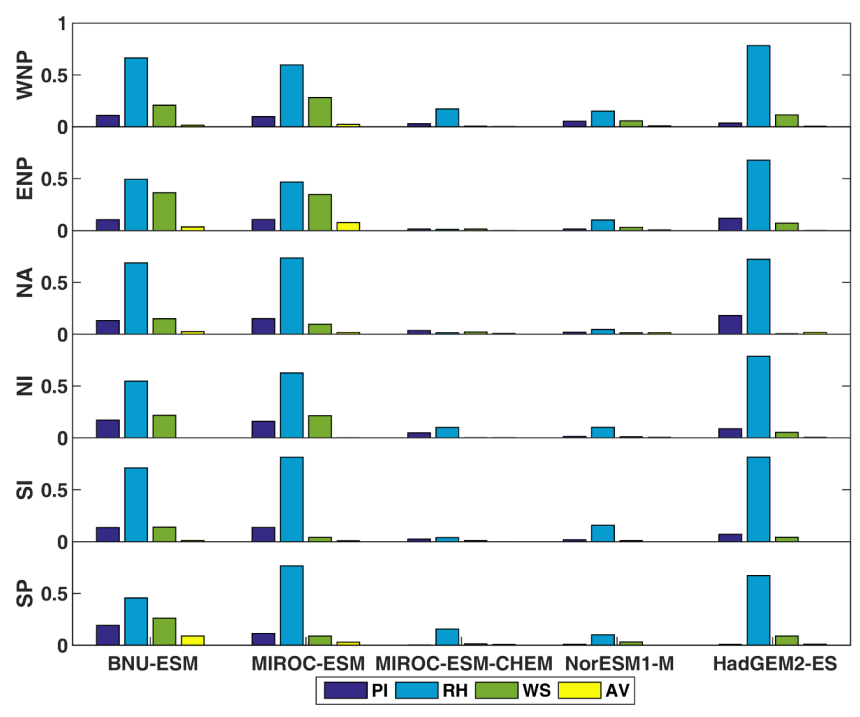

Figure 5. The fractional variance contribution of components of GPI during the TC season and within the six TC basins during 2020-2069.

$$
\begin{aligned}
\text { where } \quad \alpha_{1} & =\frac{\overline{\mathrm{RH}} \times \overline{\mathrm{AV}}}{\overline{\mathrm{WS}}} \\
\alpha_{2} & =\frac{\overline{\mathrm{PI}} \times \overline{\mathrm{AV}}}{\overline{\mathrm{WS}}} \\
\alpha_{3} & =-\frac{\overline{\mathrm{PI}} \times \overline{\mathrm{RH}} \times \overline{\mathrm{AV}}}{\overline{\mathrm{WS}}^{2}} \\
& \alpha_{4}=\frac{\overline{\mathrm{PI}} \times \overline{\mathrm{RH}}^{\overline{\mathrm{WS}}}}{\text { and } \quad} \quad \delta \mathrm{GPI}=\overline{\mathrm{GPI}}-\overline{\mathrm{GPI}} .
\end{aligned}
$$

In Eq. (6), a bar denotes an annual mean value, and $\delta$ represents the difference between an individual month and the annual mean, assuming constant coefficients for $\alpha_{1}, \alpha_{2}, \alpha_{3}$, and $\alpha_{4}$.

We are interested in detecting changes between GHG forcing alone and under SAI, so we examine the G4-RCP4.5 differences for each model grouping the TC basins by hemisphere in Fig. 4 and use $\delta \mathrm{GPI}_{\mathrm{G} 4}-\delta \mathrm{GPI}_{\mathrm{rcp} 45}$ to calculate the difference. Figure 4 clearly shows that RH and WS make the largest contribution to GPI differences in both hemispheres in all models. In the Northern Hemisphere, RH and WS terms show negative contributions in the cyclone season. Hence, these are the factors that primarily enable SAI to reduce GPI relative to GHG. In the Southern Hemisphere there are no clear difference between GPI under G4 or RCP4.5. Absolute vorticity, AV, makes almost no contribution to the GPI differences under SAI in all models.
We also do the same mathematical transform for VI. We obtain annual means and monthly anomalies:

$\delta \mathrm{VI}=\alpha_{5} \delta\left(V_{\text {pot }}\right)+\alpha_{6} \delta\left(\chi_{m}\right)+\alpha_{7} \delta\left(V_{\text {shear }}\right)$,

where $\alpha_{5}=-\overline{V_{\text {shear }}} \frac{\overline{\chi_{m}}}{\overline{V_{\text {pot }}^{2}}} \quad \alpha_{6}=\frac{\overline{V_{\text {shear }}}}{\overline{V_{\text {pot }}}} \quad \alpha_{7}=\frac{\overline{\chi_{m}}}{\overline{V_{\text {pot }}}}$

$\delta \mathrm{VI}=\mathrm{VI}-\overline{\mathrm{VI}}$.

Analogously as for GPI, we show also results for VI in Fig. 4. $V_{\text {shear }}$ makes the largest contribution to ventilation index differences between SAI and GHG forcing in both hemispheres.

\subsubsection{Contributions to GPI and VI across TC basins}

The GPI and VI dependencies may be expressed as a regression equation of $X$ on $Y$ where $Y$ is the GPI or VI anomalies under $\mathrm{G} 4$ relative to RCP4.5, and the fractional contribution to variance, $S$, of each variable $i$ in $X$ to $Y$ can be written, following Moore et al. (2006) as

$S_{i}=M_{i} C_{i} \sigma X_{i} / \sigma Y$,

where the $\sigma X$ denotes the standard deviations of the predictor terms, $\sigma Y$ denotes the standard deviation of the anomalies, $C$ denotes the correlation coefficients of the $X$ with $Y$, and $M$ denotes the regression coefficients of the $X$ with $Y$. The regression can be expressed as a multiple linear regression in log space, and the coefficients can be simply transformed after fitting. Fitting in log space also allows for the generally heteroscedastic, fractional nature of the errors in the variables.

The relative contributions to GPI anomalies from its four variable terms following the regression Eq. (8) are shown in Fig. 5. RH is the dominant factor for GPI differences in all models and all TC basins. There is little variance explained for the MIROC-ESM-CHEM and NorESM1-M models compared with the other three models. Figure 5 also shows that $\mathrm{AV}$ makes very little contribution to variance explained in the G4-RCP4.5 differences. In all models, WS makes about the same contribution as PI.

Figure $\mathrm{S} 1$ in the Supplement shows the same analysis as Fig. 5 but for all nine realizations of MIROC-ESM-CHEM. The first four realizations behave similarly as the BNU-ESM, HadGEM2-ES, and MIROC-ESM models in Fig. 5, with variance accounting for around $80 \%$ of total and the $\mathrm{RH}$ terms being about twice as important as WS and PI terms. The remaining five realizations have far lower variance explained, similar to NorESM1-M, with RH still the dominant term.

Figure S2 in the Supplement shows the three variables of the ventilation index in a similar way to Fig. 5. $V_{\text {shear }}$ makes the largest contribution to VI for all TC basins and all models, especially for the BNU-ESM and MIROC-ESM models. Figure $\mathrm{S} 3$ shows the VI components for all nine realizations of MIROC-ESM-CHEM, which appears similarly divided into two groups as they were for GPI in Fig. S1 in the 


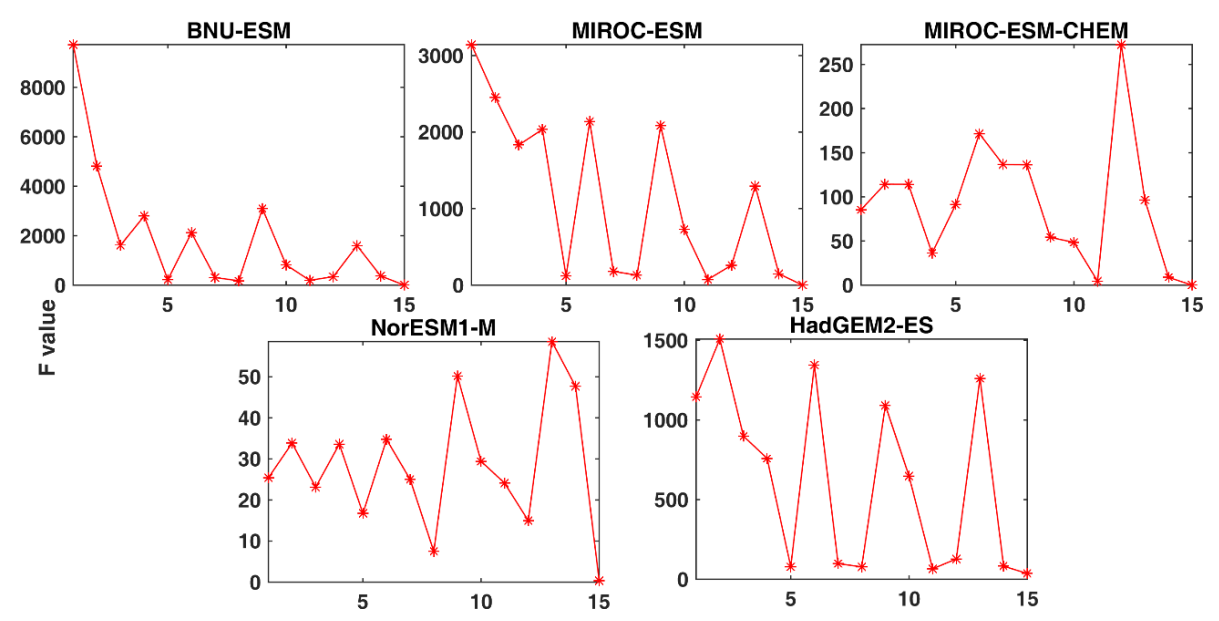

Figure 6. The $F$ statistic of the 15 different combinations of regression variables for GPI differences between G4 and RCP4.5. The $x$ axis on each panel represents the combination of components used as predictors in each regression equation: $1-\mathrm{PI}, \mathrm{RH}, \mathrm{WS}$, and AV; 2 - PI, RH, and WS; 3 - PI, RH, and AV; 4 - AV, RH, and WS; 5 - PI, AV, and WS; 6 - PI and RH; 7 - PI and WS; 8 - PI and AV; 9 - RH and WS; 10 RH and $\mathrm{AV} ; 11-\mathrm{AV}$ and WS; $12-\mathrm{PI} ; 13-\mathrm{RH} ; 14-\mathrm{WS} ; 15-\mathrm{AV}$.

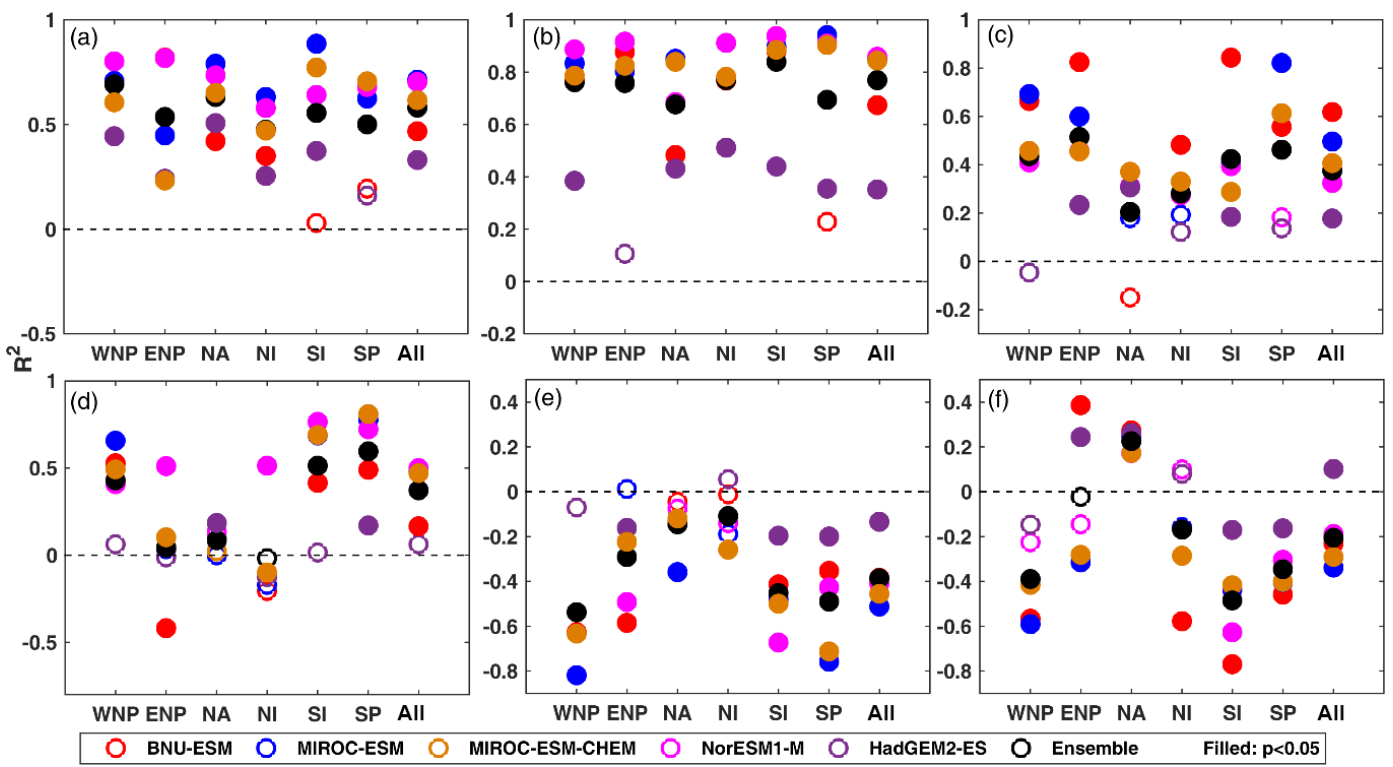

Figure 7. The correlations $\left(R^{2}\right)$ between differences (G4 - RCP4.5) during TC season and across the six TC basins for the years 2020-2069 for (a) $V_{\text {pot }}$ anomalies as a function static stability $T_{\mathrm{S}}-T_{\mathrm{O}}$. Panels (b)-(e) show $R^{2}$ coefficients for anomalies with sea surface temperature differences $\left(T_{\mathrm{S}}\right)$ and (b) $V_{\text {pot }}$, (c) GPI, (d) relative humidity, and (e) vertical wind shear. Each model is weighted equally in the ensembles regardless of number of observations.

Supplement. Indeed from Fig. S2 in the Supplement it appears that VI may be simply replaced by $V_{\text {shear }}$, for the models where any variance is explained, but viewing the month by month contributions in Fig. 4 shows that other components are relatively important for some models during some months of the TC season. $\chi_{m}$ has no consistent contribution for the models and basins.

The statistical power of a regression equation can be expressed as the $F$ statistic. Given that the different variables in Figs. 5 and S2 in the Supplement show notable differences in their contribution to the GPI and VI, we can use the $F$ statistic to examine if a reduced model with fewer variables is a better statistical model for the differences under G4 and RCP4.5. GPI has four variables, so there are 15 combination to examine, as shown in Fig. 6. Only for BNU-ESM and MIROC-ESM do the full set of variables have the highest $F$ statistic. However, HadGEM2-ES has the best model with all factors except the atmospheric vorticity term. This is consistent with results shown in Figs. 4 and 5, and with the analysis by Emanuel (2013). The value of the $F$ statis- 
tic represents the degree to which the regression model accounts for the data variability compared with the model having no independent variables. The three models that the full, or nearly full, set of variables performs best have $F$ statistics over $1000(p<0.001)$, while NorESM1-M has an $F$ value of around 25-60. This is still significant at the $99.9 \%$ level. When we analyzed realizations 5-9 of MIROC-ESMCHEM, we found much lower $F$ statistics than for realizations $1-4$ (Fig. S4 in the Supplement), with values similar to NorESM1-M of 50-100. In general, the models show RH has the largest $F$ statistic for single parameter models, which is consistent with Figs. 4 and 5. Figure S4 in the Supplement also shows that all three realizations of CanESM2, which we do not use for TC analysis in this paper, have even lower $F$ values, particularly $\mathrm{r} 2$ and $\mathrm{r} 3$, and around two of the $F$ values are not significant.

VI has three variables, so there are seven combinations possible. As with GPI in Fig. 6, there are remarkable differences in the values of $F$ amongst the models. BNUESM, MIROC-ESM, HadGEM2-ES and realizations 1-4 of MIROC-ESM-CHEM achieve values over $1000(p<0.001)$, while NorESM1-M and realizations 5-9 of MIROC-ESMCHEM have the best $F$ statistics of 50-100 ( $p<0.001)$. Figure S5 shows $V_{\text {shear }}$ has the largest contribution to VI for most of the models, and MIROC-ESM is the only model that has the largest $F$ statistic for the full set of model variables, as it also had for GPI.

\subsection{Primary factors that control GPI and VI changes}

The analysis above shows that the common factors across models and basins that affect TCs are potential intensity $\left(V_{\text {pot }}\right)$, relative humidity $(H)$, and vertical wind shear $\left(V_{\text {shear }}\right)$. We now discuss these factors separately, beginning with $V_{\text {pot }}$ as this is a function of several different ESM variables.

According to Eq. (2), $V_{\text {pot }}$ is dependent on the static stability of the troposphere, which is related to both sea surface $\left(T_{\mathrm{S}}\right)$ and upper-tropospheric temperatures $\left(T_{\mathrm{O}}\right)$ where rising air flows out of the storm. Wing et al. (2015) use the trends in reanalysis and radiosonde products at 70 and $100 \mathrm{hPa}$ in TC seasons to represent change in outflow temperature across various TC basins and assign its contribution to trends in $V_{\text {pot }}$. For convenience, we choose the tropical tropopause $(100 \mathrm{hPa})$ temperature from the ESM output to represent $T_{\mathrm{O}}$. Figure $\mathrm{S} 6$ shows the correlations across $\mathrm{TC}$ basins and seasons for the various fields in RCP4.5 and G4, while Fig. 7 shows the correlations in the differences between G4 and RCP4.5 so that the difference caused by the SAI can be clearly evaluated. Figure 7a shows the dependence of $V_{\text {pot }}$ differences (G4 - RCP4.5) on $\left(T_{\mathrm{S}}-T_{\mathrm{O}}\right)$ differences for the models. All models have significant correlation for all TC basins except BNU-ESM in the SI and SP basins and HadGEM2-ES in the SP basin. However, there is an even stronger dependence for $V_{\text {pot }}$ on $T_{\mathrm{S}}$ anomalies (Figs. 7b, S6 in the Supplement). The ensemble mean $V_{\text {pot }}$ is better correlated with $T_{\mathrm{S}}$ rather than $\left(T_{\mathrm{S}}-T_{\mathrm{O}}\right)$ due to better correlations of all models in all basins except HadGEM2-ES.

All models show significant correlation between GPI and $T_{\mathrm{S}}$ anomalies shown as Fig. 7c. Some models have insignificant correlations in particular basins; for example, BNUESM is slightly anti-correlated in NA, as is HadGEM2-ES in WNP. GPI is not significantly correlated with $T_{\mathrm{S}}$ for half the ESM in the NI and SP basins. Figure S6 shows that there are fewer significant correlations under G4 than under RCP4.5.

Figures S7 and S8 in the Supplement show the seasonal cycle of $T_{\mathrm{S}}$ and $T_{\mathrm{O}}$ for all the models. The annual cycle of $T_{\mathrm{S}}$ is very similar, as expected, for all the models, and with good agreement on the differences in seasonal cycle between the Northern Hemisphere and Southern Hemisphere as observed (Fig. S9 in the Supplement). However, for $T_{\mathrm{O}}$ the models show differences in the shapes and phases of the cycles in both hemispheres; for example, only the NorESM1$\mathrm{M}$ model shows roughly antiphase seasonality between the hemispheres. Figure S9 shows the ERA-Interim reanalysis $T_{\mathrm{O}}$ data, which have similar seasonality in both hemispheres, with peak temperature anomalies in August $\left(\sim 1.5^{\circ} \mathrm{C}\right)$ and a sharp decline to a long minimum by November or December of similar magnitude. Figs S7 shows that the models generally follow similar patterns under both G4 and RCP4.5 for $T_{\mathrm{S}}$, but Fig. $\mathrm{S} 8$ in the Supplement shows that there is much larger variability between the models' representations of $T_{\mathrm{O}}$ under $\mathrm{G} 4$ and RCP4.5. HadGEM2-ES is the model with the largest amplitude of seasonal cycle, which is somewhat larger than in ERA-Interim; other models have smaller amplitudes, with many around half that observed at present. This degree of difference in $T_{\mathrm{O}}$ simulation likely explains some of the inter-model differences in GPI.

We plot $H$ differences between $\mathrm{G} 4$ and RCP4.5 as a function of sea surface temperature differences in Fig. 7d. Relative humidity rises with warming temperatures under both G4 and RCP4.5 (Fig. S6 in the Supplement), as expected. But there are obvious differences across the ocean basins with the weakest response in ENP, NA, and NI and the strongest correlations in the Southern Hemisphere basins. The G4RCP4.5 differences follow a similar spatial pattern, with again largest correlations in the Southern Hemisphere basins.

Figure 7e shows how RCP4.5-G4 differences in $V_{\text {shear }}$ and $T_{\mathrm{S}}$ are generally anti-correlated. The across-model spread for correlations of $V_{\text {shear }}$ and $T_{\mathrm{S}}$ under both $\mathrm{G} 4$ and RCP4.5 (Fig. S6 in the Supplement) is similar to the other key variables. Anti-correlation with $T_{\mathrm{S}}$ is weakest in the SP and NA basins, but still significant. In terms of the differences in Fig. 7e, all models show clear significant anticorrelations, with the NI and NA basins having the weakest correlations. Vecchi and Soden (2007) found the North Atlantic and eastern North Pacific wind shear increases in model projections under global warming. If the models assessed here capture the effect under G4 and RCP45, we would expect positive correlations between $V_{\text {shear }}$ and $T_{\mathrm{S}}$ 
over these two basins for G4 and RCP4.5 in Fig. S6 in the Supplement.

There are similar significant relationships between $H$ and $V_{\text {shear }}$ under G4 and RCP4.5 (Fig. S6 in the Supplement) and also with their differences (Fig. 7f). This relationship is anticorrelation in all basins for most models, except in the North Atlantic. The strength of the relationship is similar to those with $T_{\mathrm{S}}$ and demonstrates that the thermodynamic variables $T_{\mathrm{S}}$ and $H$ can be useful proxies for the dynamic $V_{\text {shear }}$ variable.

\section{Discussion and conclusion}

Storms simulated by ESM may be counted using methods such as the TRACK algorithm (Hodges, 1995; Jones et al., 2017) that allow for feedbacks with the climate system. Statistical methods (Moore et al., 2015) may also implicitly include feedbacks between regional storm and background global climate conditions, but dynamical downscaling methods (Emanuel, 2013) do not include them. The GPI and VI proxies we utilize here are useful tools for relating storm activity to meteorological conditions but do not account for changes to TC tracks or intensity. Since the proxies require coarse temporal-resolution data to calculate (monthly means), compared with daily or 6-hourly data required for TRACK or the CHIPS tools, and they convey information from more than simply surface temperature fields, they may give reasonable insights into the complex changes to TC under SAI schemes.

We evaluated the hurricane index over six TC ocean basins in five CMIP5 and GeoMIP models. We used G4 and RCP4.5 experiments to assess and compare the genesis potential and ventilation indices that relate tropical storm activity to ambient meteorology. Based on the climatology of the years 2020-2069, GPI and VI both show small rising trends for TC genesis in all five models under both G4 and RCP4.5 scenarios. The TC season as measured by elevated monthly GPI values is almost a month earlier in G4 than RCP4.5, a result that is consistent across basins and models. There are fewer TCs expected globally under SAI G4 than under the purely GHG forcing of RCP4.5 as assessed by differences significant at the $95 \%$ level in both GPI and VI. All five ESM models show significantly reduced GPI under G4 in Northern Hemisphere basins (Tables 3 and 4), but results are inconclusive for southern basins. Spatial patterns of TCs show both GPI and VI predicting fewer TC in the North Atlantic and North Indian Ocean under G4 compared with RCP4.5 and more TC in the South Pacific for most models in the ensemble. Thus, the G4 scenario of SAI based on equatorial lower stratosphere injection of $\mathrm{SO}_{2}$ could lead to fewer TCs in the North Atlantic and Indian Ocean but more TCs in the South Pacific region than under GHG-induced global warming. There is, however, large inter-model variability across the six ocean basins.
Detailed statistical analysis of the two TC indices indicates that NorESM1-M and five out of nine MIROC-ESM-CHEM ensemble members have lower dependencies on explanatory variables for GPI or VI. This suggests that using GPI and VI to elucidate TC activity in those particular ESM simulations is much less reliable. It is not obvious from simple correlations between GPI and VI, or between components such as GPI or $H$ with $T_{\mathrm{S}}$, which ESM runs have relatively poor relationships for GPI.

The thermodynamic variables potential intensity and relative humidity are the dominant ones affecting genesis potential, while the dynamic variables absolute vorticity and entropy deficit are much less important. Vertical wind shear is a dynamic variable and dominates the ventilation index. By examining the contributions of variables to differences in GPI and VI under SAI and GHG forced climates, we show that relative humidity is the dominant factor for GPI differences in all models and all TC basins. Relative humidity is also usefully correlated with wind shear, though the North Atlantic displays a qualitatively different relationship than the other basins. The analysis suggests that a simplified representation of TCs depending on fewer variables may be possible but does require analysis of particular model behavior before choosing those variables. Although wind shear is important and a dynamic variable, it is encouraging that the thermodynamic state of the system is of prime importance for the GPI. This suggests that statistical methods of predicting changes in TC behavior are plausible, although individual basin behavior depends on particular local forcing factors in addition to the accessible thermodynamic variables used in the GPI and VI.

Potential intensity is related to the difference between sea surface temperature and outflow temperature (evaluated at $100 \mathrm{hPa}$ ). In fact we find that changes in SSTs alone provide a better correlation with both potential intensity and GPI changes. This result is similar to that previous observational (Grinsted et al., 2013) and modeling (Wu and Lau, 1992) studies that suggest it is the geographical distribution of SST anomalies that are crucial for the development of TC. Recent analysis of GeoMIP results by Davis et al. (2016), on the extent of the tropical belt under $\mathrm{G} 1$ and abrupt $4 \times \mathrm{CO}_{2}$ experiments, demonstrates that tropical upper-tropospheric temperature changes are well correlated with the change in global mean surface temperature. This is because changes in the static stability characterized by upper-troposphere and surface temperature differences scale with the moist adiabatic lapse rate and surface temperatures.

In contrast with the solar dimming G1 experiments analyzed by Davis et al. (2016), here we analyze G4, which is an aerosol injection protocol. The aerosol is prescribed (Kravitz et al., 2011) as injected into the equatorial stratosphere at $16-25 \mathrm{~km}$ altitude, where most of the direct radiative heating takes place (Pitari et al., 2014). However, due to the large size of the geoengineering aerosol particles (effective radius of the order of $0.6 \mu \mathrm{m}$ or more), a significant 
fraction of the stratospheric particles settle below the tropical tropopause (Niemeier et al., 2011; English et al., 2012; Cirisan et al, 2013), thus producing some diabatic heating a few kilometers immediately below the tropical tropopause. This is superimposed on the convectively driven uppertropospheric cooling caused by surface cooling due to the SAI and reduced convection and weakened hydrological cycle (Bala et al., 2008). This may be expected to be the dominant process controlling the SAI-induced changes in atmospheric static stability. Furthermore, recent work (Visioni et al., 2018) explores the surface cooling impact on uppertropospheric cirrus cloud formation, as well as the concomitant impact on static stability. Surface cooling and lower stratospheric warming, together, tend to stabilize the atmosphere, thus decreasing turbulence and updraft velocities. The net effect is an induced cirrus thinning, which indirectly increases net global cooling due to the SAI.

Pitari et al. (2014) note a warming of the $100 \mathrm{hPa}$ layer under G4 relative to RCP4.5 for the MIROC-ESM-CHEM model in the 2040s for the tropics. Most models (Table 3) in the TC basins and seasons show a cooling (ensemble mean of $0.14 .{ }^{\circ} \mathrm{C}$ ), with only HadGEM2-ES and BNU-ESM having a warming at $100 \mathrm{hPa}$. Given the complexities of changes in the upper troposphere due to the process outlined in the previous paragraph, the range in static stabilities represented by the model range in $T_{\mathrm{S}}-T_{\mathrm{O}}$ differences relative to RCP4.5 is probably not surprising. Therefore, although we might expect to see an improvement in correlation of potential intensity and GPI by using $100 \mathrm{hPa}$ temperatures in addition to SSTs, the ability of the models to capture all the processes varies. The result is that the models used here have a better relationship with sea surface temperatures than static stability, and this suggests that the aerosol effects are not being simulated well enough to allow their impacts on TC genesis to be fully estimated.

The change in relative humidity on the tropical ocean basins in the future is a key aspect of TC genesis according to our analysis. Models tend to agree on the sign of change in relative humidity as temperatures rise, but there are consistent differences in response strength across the ocean basins. This indicates that, although relative humidity is important for most models, changes in TC genesis processes between basins affect their utility as a predictor variable. Here we used the widely utilized formulation of GPI given by Emanuel and Nolan (2004), which specified moisture in terms of relative humidity. More recently Emanuel (2010) reformulated the GPI in terms of "saturation deficit" that is a measure of the moist entropy deficit of the middle troposphere, which becomes larger as the middle troposphere becomes drier. This parameter has the same denominator as $\chi_{m}$ in Eq. (4), which is used in the calculation of VI, Eq (3), while the numerator varies only in the definition of the boundary layer. Our analysis of the dependence of the three terms that describe VI shows $\chi_{m}$ is moderately important in some models (Fig. S5 in the Supplement), and we can see the $F$ value of ( $\left.V_{\text {pot }} \chi_{m}\right)$ or $\left(V_{\text {shear }} \chi_{m}\right)$ is larger than $\left(V_{\text {pot }} V_{\text {shear }}\right)$ in all models. This is consistent with the analysis of six ESM models of 21 st century trends in GPI by Emanuel (2013), who also notes that vorticity does not contribute to trends.

The final variable, $V_{\text {shear }}$, shows large scatter across the models, but is consistent anti-correlation with $T_{\mathrm{S}}$. However, there are also good but different relations between $H$ and $V_{\text {shear }}$ in every basin, suggesting that the state of this dynamic variable can be explained to a significant degree by the thermodynamic state driving $H$ and $T_{\mathrm{S}}$. This is consistent with the analysis of Li et al. (2010) showing that prescribed sea surface temperatures can account for some changes in TC in the Pacific basins as surface temperature gradients drive trade winds, which changes the wind shear. Overall our analysis of the driving parameters in GPI suggests that, despite large model differences, the simple dependence of GPI on surface temperatures is reasonably robust.

Smyth et al. (2017) report the seasonal migration of the Intertropical Convergence Zone (ITCZ) in G1, associated with preferential cooling of the summer hemisphere, and annual mean ITCZ shifts in some models that are correlated with the warming of one hemisphere relative to the other. ITCZ location is correlated with TC and season. The timing of the TC season under G4 is about a month earlier in both hemispheres than under RCP4.5. This might also be a function of the reduced amplitude of ITCZ motion, though this effect has not yet been verified as occurring under SAI as prescribed by G4. It is plausible because reduced solar heating of the ocean basins means that less sea water is heated and there will be reduced lag of those surface waters with solar zenith position. Our analysis of seasonality of TCs shows that there appears to be a difference in behavior between the Southern Hemisphere and Northern Hemisphere, with the southern one showing no consistent changes between models under RCP4.5 and G4 scenarios. Davis et al. (2016) show that there are differences in the evolution of the northern and southern Hadley cells under GHG forcing, with the expansion of the northern one scaling nonlinearly with temperature. Differences seem to be driven fundamentally by the equator-pole temperature gradient and therefore may be expected given the far greater fraction of land surface and larger polar amplification in the Northern Hemisphere.

Considering the coarse spatiotemporal resolution of most ESM models, evaluating the GPI is likely to remain popular and be a good diagnostic of TC variability under different climates. The results presented here suggest that SAI produces reductions in TCs across most of the major storm basins, and this is primarily due to reduced sea surface temperatures in the genesis regions. 
Data availability. The raw G4 and RCP4.5 data are archived at https://esgf-data.dkrz.de/search/esgf-dkrz/. The CanESM2 and NorESM1-M data are archived by the modeling team. The BNUESM data are archived at http://esg.bnu.edu.cn/BNU_ESM_webs/ htmls/data_acc.html.

\section{The Supplement related to this article is available online at https://doi.org/10.5194/acp-18-9173-2018-supplement.}

Author contributions. JM, DJ and QW conceived and designed the analysis. QW mainly collected all model data and performed the analysis, QW wrote the paper, and JM and DJ provided critical suggestions and revised the paper.

Competing interests. The authors declare that they have no conflict of interest.

Acknowledgements. We thank two anonymous referees for very constructive comments, the climate modeling groups for participating in the Geoengineering Model Intercomparison Project, and their model development teams; the CLIVAR/WCRP Working Group on Coupled Modeling for endorsing the GeoMIP; and the scientists managing the earth system grid data nodes who have assisted with making GeoMIP output available. This research was funded by the National Basic Research Program of China (grant 2015CB953600) and the Fundamental Research Funds for the Central Universities (312231103).

Edited by: Gabriele Stiller

Reviewed by: two anonymous referees

\section{References}

Bala, G., Duffy, P. B., and Taylor, K. E.: Impact of geoengineering schemes on the global hydrological cycle, P. Natl. Acad. Sci., 105, 7664-7669, https://doi.org/10.1073/pnas.0711648105, 2008.

Balaguru, K., Foltz, G. R., Leung, L. R., Asaro, E. D’, Gabriel, K. A., Liu, H., and Zedler, S. E.: Dynamic Potential Intensity: An improved representation of the ocean's impact on tropical cyclones, Geophys. Res. Lett., 42, 6739-6746, 2015.

Bentsen, M., Bethke, I., Debernard, J. B., Iversen, T., Kirkevåg, A., Seland, Ø., Drange, H., Roelandt, C., Seierstad, I. A., Hoose, C., and Kristjánsson, J. E.: The Norwegian Earth System Model, NorESM1-M - Part 1: Description and basic evaluation of the physical climate, Geosci. Model Dev., 6, 687-720, https://doi.org/10.5194/gmd-6-687-2013, 2013.

Bister, M. and Emanuel, K. A.: The genesis of Hurricane Guillermo: TEXMEX analyses and a modeling study, Mon. Weather Rev., 125, 2662-2682, 1997.

Bister, M. and Emanuel, K. A.: Dissipative heating and hurricane intensity, Meteor. Atmos. Phys., 65, 233-240, 1998.
BNU: BNU-ESM CMIP5 data, available at: http://esg.bnu.edu. cn/BNU_ESM_webs/htmls/data_acc.html, last access: 27 June 2018.

Chan, J. C. L.: Interannual and interdecadal variations of tropical cyclone activity over the western North Pacific, Meteor. Atmos. Phys., 89, 143-52, 2005.

Cirisan, A., Spichtinger, P., Luo, B. P., Weisenstein, D. K., Wernli, H., Lohmann, U., and Peter, T.: Microphysical and radiative changes in cirrus clouds by geoengineering the stratosphere, J. Geophys. Res.-Atmos., 118, 4533-4548, https://doi.org/10.1002/jgrd.50388, 2013.

Collins, W. J., Bellouin, N., Doutriaux-Boucher, M., Gedney, N., Halloran, P., Hinton, T., Hughes, J., Jones, C. D., Joshi, M., Liddicoat, S., Martin, G., O'Connor, F., Rae, J., Senior, C., Sitch, S., Totterdell, I., Wiltshire, A., and Woodward, S.: Development and evaluation of an Earth-System model - HadGEM2, Geosci. Model Dev., 4, 1051-1075, https://doi.org/10.5194/gmd-4-10512011, 2011.

Crutzen, P. J.: Albedo enhancement by stratospheric sulfur injections: A contribution to resolve a policy dilemma?, Clim Change, 77, 211-220, 2006.

Davis, N. A., Seidel, D. J., Birner, T., Davis, S. M., and Tilmes, S.: Changes in the width of the tropical belt due to simple radiative forcing changes in the GeoMIP simulations, Atmos. Chem. Phys., 16, 10083-10095, https://doi.org/10.5194/acp-16-100832016, 2016.

DKRZ: ESGF Node at DKRZ, available at: https://esgf-data.dkrz. de/search/esgf-dkrz/, last access: 27 June 2018.

Emanuel, K. A.: Atmospheric Convection, Oxford University Press, 580 pp., 1994.

Emanuel, K. A.: A statistical analysis of tropical cyclone intensity, Mon. Weather Rev., 128, 1139-1152, 2000.

Emanuel, K. A.: Climate and tropical cyclone activity: A new model downscaling approach, J. Climate, 19, 4797-4802, 2006.

Emanuel, K. A.: Tropical cyclone activity downscaled from NOAACIRES reanalysis, J. Adv. Model. Earth Syst., 2, 1-12, 19081958, 2010.

Emanuel, K. A.: Downscaling CMIP5 climate models shows increased tropical cyclone activity over the 21 st century, P. Natl Acad. Sci., 110, 12219-12224, 2013.

Emanuel, K. A. and Nolan, D.: Tropical cyclone activity and global climate system, Am. Meteorol. Soc., 26, 240-241, 2004.

Emanuel, K. A., Sundararajan, R., and Williams, J.: Hurricanes and global warming: Results from downscaling IPCC AR4 simulations, B. Am. Meteor. Soc., 89, 347-367, 2008.

English, J. M., Toon, O. B., and Mills, M. J.: Microphysical simulations of sulfur burdens from stratospheric sulfur geoengineering, Atmos. Chem. Phys., 12, 4775-4793, https://doi.org/10.5194/acp-12-4775-2012, 2012.

Gray, W. M.: Hurricanes: Their formation, structure, and likely role in the tropical circulation, Roy. Meteor. Soc., 155-218, 1979.

Grinsted, A., Moore, J. C., and Jevrejeva, S.: A homogeneous record of Atlantic hurricane surge threat since 1923, P. Natl. Acad. Sci., 109, 19601-19605, 2012.

Grinsted, A., Moore, J. C., and Jevrejeva, S.: Projected Atlantic tropical cyclone threat from rising temperatures, P. Natl. Acad. Sci., 110, 5369-5373, 2013.

Hodges, K.: Feature tracking on a unit sphere, Mon. Weather Rev., 123, 3458-3465, 1995. 
Huneeus, N., Boucher, O., Alterskj, K., Cole, J. N. S., Curry, C. L., Ji, D., Jones, A., Kravitz, B., Kristjánsson, J. E., Moore, J. C., Muri, H., Niemeier, U., Rasch, P., Robock, A., Singh, B., Schmidt, H., Schulz, M., Tilmes, S., Watanabe, S., and Yoon, J.H.: Forcings and feedbacks in the GeoMIP ensemble for a reduction in solar irradiance and increase in $\mathrm{CO}_{2}$, J. Geophys. Res.Atmos., 119, 5226-5239, 2014.

IPCC: Climate Change 2007: Synthesis Report. Contribution of Working Groups I, II and III to the Fourth Assessment Report of the Intergovernmental Panel on Climate Change, edited by: Core Writing Team, R. K. Pachauri, and A. Reisinger, 104 pp., IPCC, Geneva, Switzerland, 2007.

Ji, D., Wang, L., Feng, J., Wu, Q., Cheng, H., Zhang, Q., Yang, J., Dong, W., Dai, Y., Gong, D., Zhang, R.-H., Wang, X., Liu, J., Moore, J. C., Chen, D., and Zhou, M.: Description and basic evaluation of Beijing Normal University Earth System Model (BNU-ESM) version 1, Geosci. Model Dev., 7, 2039 2064, https://doi.org/10.5194/gmd-7-2039-2014, 2014.

Jones, A. C., Haywood, J. M., Dunstone, N., Emanuel, K., Hawcroft, M. K., Hodges, K. I., and Jones, A.: Impacts of hemispheric solar geoengineering on tropical cyclone frequency, Nat. Commun., 8, 1-10, 2017.

Kashimura, H., Abe, M., Watanabe, S., Sekiya, T., Ji, D., Moore, J. C., Cole, J. N. S., and Kravitz, B.: Shortwave radiative forcing, rapid adjustment, and feedback to the surface by sulfate geoengineering: analysis of the Geoengineering Model Intercomparison Project G4 scenario, Atmos. Chem. Phys., 17, 3339-3356, https://doi.org/10.5194/acp-17-3339-2017, 2017.

Knutson, T. R., Mcbride, J. L., Chan, J., Emanuel, K., Holland, G., Landsea, C., Held, I., Kossin, J. P., Srivastava, A. K., and Sugi, M.: Tropical cyclones and climate change, Nat. Geosci., 3, 157163, https://doi.org/10.1038/ngeo779, 2010.

Knutson, T. R., Sirutis, J., Zhao, M., Tuleya, R., Bender, M., Vecchi, G., Villarini, G., and Chavas, D.: Global projections of intense tropical cyclone activity for the late twenty-first century from dynamical downscaling of CMIP5/RCP4.5 scenarios, J. Climate, 28, 7203-7224, 2015.

Kravitz, B., Robock, A., Boucher, O., Schmidt, H., Taylor, K. E., Stenchikov, G., and Schulz, M.: The Geoengineering Model Intercomparison Project (GeoMIP), Atmos. Sci. Lett., 12, 162167, 2011.

Kravitz, B., Robock, A., Tilmes, S., Boucher, O., English, J. M., Irvine, P. J., Jones, A., Lawrence, M. G., MacCracken, M., Muri, H., Moore, J. C., Niemeier, U., Phipps, S. J., Sillmann, J., Storelvmo, T., Wang, H., and Watanabe, S.: The Geoengineering Model Intercomparison Project Phase 6 (GeoMIP6): simulation design and preliminary results, Geosci. Model Dev., 8, 33793392, 2015.

Landsea, C. W.: Hurricanes and global warming, Nature, 438, E11E12, 2005.

Li, T., Kwon, M., Zhao, M., Kug, J. S., Luo, J. J., and Yu, W.: Global warming shifts Pacific tropical cyclone location, Geophys. Res. Lett., 37, L21804, https://doi.org/10.1029/2010GL045124, 2010.

Li, Z., Yu, W., Li, T., Murty, V. S., and Tangang F.: Bimodal Character of Cyclone Climatology in the Bay of Bengal Modulated by Monsoon Seasonal Cycle, J. Climate, 26, 1033-1046, 2013.

Moore, J. C., Kekonen, T., Grinsted, A., and Isaksson, E.: Sulfate source inventories from a Svalbard ice core record span- ning the Industrial Revolution, J. Geophys. Res., 111, D15307, https://doi.org/10.1029/2005JD006453, 2006.

Moore, J. C., Grinsted, A., Guo, X., Yu, X., Jevrejeva, S., Rinke, A., Cui, X., Kravitz, B., Lenton, A., Watanabe, S., and Ji, D.: Atlantic hurricane surge response to geoengineering, P. Natl. Acad. Sci., 112, 13794-13799, 2015.

Niemeier, U., Schmidt, H., and Timmreck, C.: The dependency of geoengineered sulfate aerosol on the emission strategy, Atmos. Sci. Lett., 12, 189-194, https://doi.org/10.1002/asl.304, 2011.

Nolan, D. S.: What is the trigger for tropical cyclogenesis?, Aust. Meteorol. Mag., 56, 241-266, 2007.

Pitari, G., Aquila, V., Kravitz, B., Robock, A., Watanabe, S., Cionni, I., Luca N. D., Genova, G. D., Mancini, E., and Tilmes, S.: Stratospheric ozone response to sulfate geoengineering: Results from the Geoengineering Model Intercomparison Project (GeoMIP), J. Geophys. Res.-Atmos., 119, 2629-2653, 2014.

Rappin, E. D., Nolan, D. S., and Emanuel, K. A.: Thermodynamic control of tropical cyclogenesis in environments of radiative convective equilibrium with shear, Q. J. Roy. Meteorol. Soc., 136, 1954-1971, 2010.

Riehl, H.: A model for hurricane formation, J. Appl. Phys., 21, $917-$ 925, 1950.

Rogelj, J., Luderer, G., Pietzcker, R. C., Kriegler, E., Schaeffer, M., Krey, V., and Riahi, K.: Energy system transformations for limiting end-of-century warming to below $1.5^{\circ} \mathrm{C}$, Nature Clim Change, 5, 519-527, 2015.

Russotto, R. D. and Ackerman, T. P.: Energy transport, polar amplification, and ITCZ shifts in the GeoMIP G1 ensemble, Atmos. Chem. Phys., 18, 2287-2305, https://doi.org/10.5194/acp18-2287-2018, 2018.

Smyth, J. E., Russotto, R. D., and Storelvmo, T.: Thermodynamic and dynamic responses of the hydrological cycle to solar dimming, Atmos. Chem. Phys., 17, 6439-6453, https://doi.org/10.5194/acp-17-6439-2017, 2017.

Song, Y. J., Wang, L., Lei, X. Y., and Wang, X. D.: Tropical cyclone genesis potential index over the western North Pacific simulated by CMIP5 models, Adv. Atmos. Sci., 32, 1539-1550, 2015.

Tang, B. and Emanuel, K. A.: A ventilation index for tropical cyclones, B. Am. Meteor. Soc., 93, 1901-1912, 2012.

Tang, B. and Camargo, S. J.: Environmental control of tropical cyclones in CMIP5: A ventilation perspective, J. Adv. Model. Earth Syst., 6, 115-128, 2014.

Taylor, K. E., Stouffer, R. J., and Meehl, G. A.: An overview of CMIP5 and the experiment design, B. Am. Meteor. Soc., 93, 485-498, 2012.

Tippett, M. K., Camargo, S. J., and Sobel, A. H.: A Poisson regression index for tropical cyclone genesis and the role of large-scale vorticity in genesis, J. Climate, 24, 2335-2357, 2011.

Tory, K. J., Chand, S. S., McBride, J. L., Ye, H., and Dare, R. A.: Projected Changes in Late-Twenty-First-Century Tropical Cyclone Frequency in 13 Coupled Climate Models from Phase 5 of the Coupled Model Intercomparison Project, J. Climate, 26, 9946-9959, 2013

Vecchi, G. A. and Soden, B. J.: Increased tropical Atlantic wind shear in model projections of global warming, Geophys. Res. Lett., 34, L08702, https://doi.org/10.1029/2006GL028905, 2007.

Visioni, D., Pitari, G., and Aquila, V.: Sulfate geoengineering: a review of the factors controlling the needed injec- 
tion of sulfur dioxide, Atmos. Chem. Phys., 17, 3879-3889, https://doi.org/10.5194/acp-17-3879-2017, 2017.

Visioni, D., Pitari, G., and di Genova, G.: Upper tropospheric ice sensitivity to sulfate geoengineering, Atmos. Chem. Phys. Discuss., https://doi.org/10.5194/acp-2018-107, in review, 2018.

Watanabe, S., Hajima, T., Sudo, K., Nagashima, T., Takemura, T., Okajima, H., Nozawa, T., Kawase, H., Abe, M., Yokohata, T., Ise, T., Sato, H., Kato, E., Takata, K., Emori, S., and Kawamiya, M.: MIROC-ESM 2010: model description and basic results of CMIP5-20c3m experiments, Geosci. Model Dev., 4, 845-872, https://doi.org/10.5194/gmd-4-845-2011, 2011.

Wigley, T. M. L.: A combined mitigation/geoengineering approach to climate stabilization, Science, 314, 452-454, 2006.
Wing, A. A., Emanuel, K., and Solomon, S.: On the factors affecting trends and variability in tropical cyclone potential intensity, Geophys. Res. Lett., 42, 8669-8677, https://doi.org/10.1002/2015GL066145, 2015.

Wu, G. and Lau, N.-C.: A GCM simulation of the relationship between tropical-storm formation and ENSO, Mon. Weather Rev., 120, 958-977, 1992.

Yu, X., Moore, J. C., Cui, X., Rinke, A., Ji, D., Kravitz, B., and Yoon, J.-H.: Impacts, effectiveness and regional inequalities of the GeoMIP G1 to G4 solar radiation management scenarios, Global Planet. Change, 129, 10-22, 2015. 